\title{
Persistence and metabolism of the diamide insecticide cyantraniliprole in tomato plants
}

\author{
Khang Huynh ${ }^{1}$, Elizabeth Leonard ${ }^{1}$, Juang-Horng Chong ${ }^{2}$, Cristi Palmer $^{3}$ \& \\ Nishanth Tharayil ${ }^{\bowtie}$
}

Plant uptake and metabolism of pesticides are complex and dynamic processes, which contribute to the overall toxicity of the pesticides. We investigated the metabolic fate of cyantraniliprole, a new diamide class of insecticide, during various growth stages of tomato. Cyantraniliprole was the major residue in leaves, flowers, and fruits, with the relative metabolite-to-parent ratios maintained at $<10 \%$ up to 28 days after treatment (DAT). Mature leaves contained consistently higher residues of cyantraniliprole than young leaves throughout the study. Flowers contained the highest cyantraniliprole residues up to 21 DAT, then gradually decreased. Immature green fruits had the highest cyantraniliprole residues $(5.3 \pm 0.7 \mathrm{ng} / \mathrm{g} ; 42 \mathrm{DAT})$, and decreased toward red ripening stages $(1.4 \pm 0.2 \mathrm{ng} / \mathrm{g} ; 84 \mathrm{DAT})$. Metabolism of cyantraniliprole primarily occurred in the foliage, where 21 metabolites were tentatively identified. Flowers and fruits contained 14 and four of these metabolites, respectively. Major transformation pathways were characterized by ring closure, followed by $\mathrm{N}$-demethylation, and glycosylation. Additionally, plant metabolism of cyantraniliprole was also associated with several minor phase-I, phase-II, and breakdown metabolites. The occurrence of these metabolites in plants varied as a function of tissue types and their developmental stages. Our study highlights a tissue-specific biotransformation and accumulation of metabolites of cyantraniliprole in tomato.

Pesticides are the mainstay of modern agriculture, enabling growers to reduce pest infestation in crops. However, widespread pesticide use has also prompted persistent public concerns over the adverse effects of residues on non-target organisms and human health. Partly driven by this concern, over the past decades, the amount of pesticides used in the United States has been reduced by approximately $40 \%$, shifting toward pyrethroids and neonicotinoids, which are less toxic to birds and mammals ${ }^{1}$. Unfortunately, this shifting trend has exerted significant threats to some plant species and invertebrates (e.g., pollinators) ${ }^{1}$. Besides, incidences of resistance to pyrethroids and neonicotinoids have also been reported worldwide ${ }^{2-7}$, necessitating the introduction of new chemistries for pest management.

In this context, recently introduced diamide insecticides have been considered the most promising alternative, in large part due to their lower toxicity to beneficial arthropods, mammals, and pollinators ${ }^{8-10}$. Diamide insecticides target insects' ryanodine receptors and trigger uncontrolled release of internal calcium stores; consequently, the exposed insects suffer feeding cessation, lethargy, muscle paralysis, and eventually death ${ }^{11}$. Anthranilic diamides, such as cyantraniliprole and chlorantraniliprole, can be delivered via seed treatment, soil, or foliar applications to manage a broad-spectrum of chewing and sap sucking pests on several plant species ${ }^{12-14}$. Recent studies have suggested that soil application or seed treatment of cyantraniliprole and chlorantraniliprole could provide greater efficacy than foliar spray ${ }^{15}$ or equivalent level of pest protection compared to neonicotinoid seed treatment ${ }^{8}$, thereby reducing negative impacts on non-target species and environmental health concerns, and a potentially long residual effect post-application ${ }^{8,15}$. Nevertheless, their persistence in soils may result in a prolonged exposure of the treated crops and pests to the insecticides, potentially leading to increased bioaccumulation of the residues inside plant tissues and insecticide resistance ${ }^{16}$. Although the long residual efficacy of anthranilic diamides against pest infestation has been well-studied ${ }^{8,10,15}$, the metabolic pathways and distribution patterns of the residues and metabolites in crops during this prolonged exposure is less known. Furthermore, root

\footnotetext{
${ }^{1}$ Department of Plant and Environmental Sciences, Clemson University, Clemson, SC 29634, USA. ${ }^{2}$ Department of Plant and Environmental Sciences, Pee Dee Research and Education Center, Clemson University, Florence, SC 29506, USA. ${ }^{3}$ Rutgers, The State University of New Jersey, IR-4 Project, New Brunswick, NJ 08901, USA. ${ }^{\square}$ email: ntharay@clemson.edu
} 
(A)

(B)
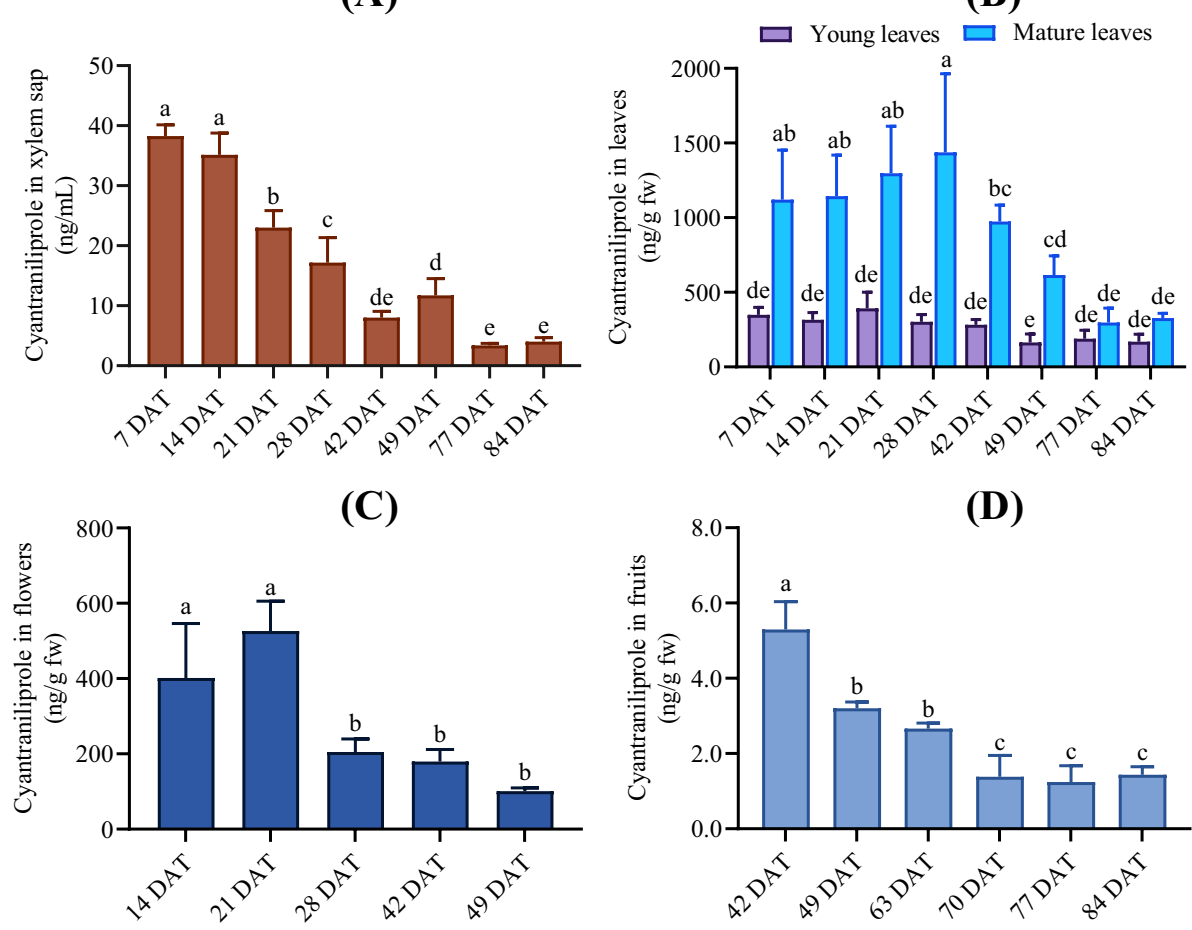

Figure 1. Concentrations of cyantraniliprole in xylem sap (A), leaves (B), flowers (C), and fruits (D) of tomato plants at different sampling times after treatment with Mainspring GNL. The values represent the means \pm standard deviation $(n=5)$. Columns within the same graph topped by different letters are significantly different from each other $(p<0.05)$.

uptake and transport of systemic insecticides largely depend on their physiochemical properties, leading to different distribution patterns and metabolite concentrations inside plant tissues compared to foliar application ${ }^{17,18}$. Plant detoxification systems are also influenced by environmental and physiological factors during the plant's life cycle $^{19}$, resulting in ontogeny-/tissue-dependent metabolite profiles. It has been shown that, in addition to the parent compounds, some insecticide metabolites may also retain insecticidal activity and could contribute to the overall toxicity of the residues ${ }^{20-23}$. Therefore, a comprehensive understanding of the metabolic fate and behavior of insecticides in plant tissues is of great importance for informing risk assessment.

In the present study, the uptake and distribution of soil-applied cyantraniliprole in different tissues of tomato plants (Solanum lycopersicum L.) and the associated transformation pathways were investigated. Tomato is an economically important crop around the world ${ }^{24}$ and represents a fruiting vegetable in which cyantraniliprole is effective against several insect pests (e.g., armyworm, aphids, hornworm, leafminer, loopers, psyllids, thrips, and whitefly) ${ }^{25,26}$. Targeted and untargeted metabolomics using high resolution mass-spectral information was used to identify the metabolite candidates, as well as variations in the metabolite profiles in the foliage, flowers, and fruits across different developmental stages of the tomato plants.

\section{Results and discussion}

Residues of cyantraniliprole in xylem saps and plant tissues. No phytotoxicity was observed for the plants treated with cyantraniliprole throughout the study, and the treated plants showed equivalent growth and development compared to the control plants. Following soil application, cyantraniliprole was quickly absorbed by roots and transported acropetally via the evapotranspiration stream in xylem. The highest concentrations of cyantraniliprole in the xylem sap were observed at 7 and 14 DAT $(38.3 \pm 1.9$ and $35.1 \pm 3.7 \mathrm{ng} / \mathrm{mL}$, respectively) and decreased gradually in subsequent samples, reaching $4.0 \pm 0.7 \mathrm{ng} / \mathrm{mL}$ at $84 \mathrm{DAT}$ (Fig. 1A). Cyantraniliprole was also detected in all plant tissues at all sampling intervals up to fruit maturity, with residue concentrations declining in the order of foliage $>$ flowers $>$ fruits (Fig. 1). In the foliage, there was significant interaction between leaf age and sampling interval in determining residue concentrations $(p<0.001)$. The highest concentrations were found in mature leaves, increased from $1120.3 \pm 332.3 \mathrm{ng} / \mathrm{g}$ at 7 DAT to $1437.8 \pm 525.8 \mathrm{ng} / \mathrm{g}$ at 28 DAT. During the same period (7-28 DAT), the concentrations of cyantraniliprole accumulated in young (apical) leaves were significantly lower than those in mature leaves $(p<0.001)$, but similar among young leaves sampled at different times (ranged from $303.0 \pm 47.3$ at $28 \mathrm{DAT}$ to $392.4 \pm 108.1 \mathrm{ng} / \mathrm{g}$ at $21 \mathrm{DAT}$ ). After $28 \mathrm{DAT}$, residue concentrations in mature leaves decreased considerably, but those in young leaves decreased only slightly as sampling progressed, thus reducing difference between young and mature leaves. At 84 DAT, residues in mature and young leaves were $327.1 \pm 32.1 \mathrm{ng} / \mathrm{g}$ and $169.3 \pm 49.8 \mathrm{ng} / \mathrm{g}$, respectively. Flowers exhibited peak residue con- 
centration at 21 DAT $(526.3 \pm 79.4 \mathrm{ng} / \mathrm{g})$ but decreased rapidly, reaching $101.3 \pm 8.4 \mathrm{ng} / \mathrm{g}$ at the last flower harvest (49 DAT). Concentrations of cyantraniliprole in flowers were similar to those in young leaves $(p=0.67)$. In fruits, cyantraniliprole residue decreased with sampling intervals from its highest concentration at the immature green stage (42 DAT; $5.3 \pm 0.7 \mathrm{ng} / \mathrm{g}$ ) to its lowest at the red ripening stage (84 DAT; $1.4 \pm 0.2 \mathrm{ng} / \mathrm{g}$ ).

Since phloem mobility is absent, xylem flux was the predominant driving force that distributed cyantraniliprole throughout the plants following root uptake ${ }^{15,25,27}$. Accordingly, the higher residue concentrations in mature leaves compared with other tissues may be explained by the relative position and flow velocity for each respective plant tissues within the evapotranspiration stream ${ }^{25}$. Young leaves and flowers located in the positions of the farthest upward-transport along the xylem flux from soil pore water to plant apex. On the other hand, appreciable discrepancies in relative surface area of tomato leaves $\left(6 \mathrm{~m}^{2} / \mathrm{kg}\right)$ and fruits $\left(0.16 \mathrm{~m}^{2} / \mathrm{kg}\right)^{25}$ suggested that the xylem flux for leaves to be significantly larger than for fruits. Tomato leaves transpire water through stomata on the surfaces, creating a driving force for water and soluble compounds flow into leaf tissues, as opposed to fruits, which lack stomata ${ }^{28,29}$. Consequently, significantly lower concentrations of cyantraniliprole were found in the fruits compared to young leaves and mature leaves at all sampling intervals $(p<0.001)$. The reduction in cyantraniliprole concentrations in all plant tissues with the progression of sampling time can be explained by growth dilution effect and plant metabolism in the respective tissues, as well as a lower cyantraniliprole uptake from the growing medium as supported by the change in concentrations of the insecticide in xylem sap.

Metabolic fate of cyantraniliprole in tomato plants. Due to the lack of reference standards, the metabolites of cyantraniliprole identified in the present study were confirmed at various confidence levels based on the framework proposed by Schymanski et al. ${ }^{30}$. The identification was based on the following criteria: (1) mass error $<5 \mathrm{ppm}$ for the calculated and observed accurate $m / z$; (2) $\mathrm{Cl} / \mathrm{Br}$ isotope patterns; (3) the proposed formulas obey the nitrogen rule ${ }^{31}$; and (4) the proposed chemical structures can be fully explained by $\mathrm{MS}^{2}$ fragment ions. Those metabolites with inadequate $\mathrm{MS}^{2}$ characteristic fragments were assigned to the lowest confidence level (level 5).

In this study, a total of 21 metabolites were tentatively identified in different tissues of the tomato plants treated with cyantraniliprole, including those that were reported in the registration documents ${ }^{32}$ as well as several new metabolites (Table 1). For example, the metabolite at $\mathrm{m} / z 455.0022$ was detected in all treatments at a retention time of $11.04 \mathrm{~min}$. The proposed elemental composition for this metabolite is $\mathrm{C}_{19} \mathrm{H}_{12} \mathrm{BrClN}_{6} \mathrm{O}$, with a mass error of $1.1 \mathrm{ppm}$. Its isotope pattern was consistent with a molecule containing one bromine and one chlorine atom. Based on its accurate $\mathrm{m} / \mathrm{z}$ and proposed formula, this metabolite was proposed as IN-J9Z38, a major metabolite of cyantraniliprole reported in previous studies ${ }^{32-34}$. $\mathrm{MS}^{2}$ fragment ions were subsequently used to confirm the chemical structure (Fig. S2). Similarly, the accurate masses of metabolite TP651 $(\mathrm{m} / z 651.0608$ at RT $=6.53 \mathrm{~min}$ and $m / z 651.0616$ at $\mathrm{RT}=7.21 \mathrm{~min}$ ) allowed the prediction of the chemical formula $\mathrm{C}_{25} \mathrm{H}_{24} \mathrm{BrClN}_{6} \mathrm{O}_{8}$ with a mass error of 1.2 and $2.5 \mathrm{ppm}$, respectively. $\mathrm{MS}^{2}$ fragmentation revealed identical product ions at $m / z 489.00$, which is the characteristic molecular ion of hydroxylated cyantraniliprole. Addition of an anhydroglucose moiety $(162.05 \mathrm{Da})$ suggested the formation of glycosylated metabolites (Figs. S17 and S18). The same approach was used for identification and confirmation of the remaining metabolites (Table 1). Out of 21 metabolites tentatively identified, 11 compounds were phase-I transformation products, six compounds were phase-II conjugates, and four compounds were breakdown products. In general, cyantraniliprole lacks the functional groups suitable for direct phase-II conjugation reactions (e.g., $\mathrm{OH}-, \mathrm{NH}_{2}-$ ), which requires activation via phase-I reactions. This may explain the predominant presence of phase-I transformation products in the metabolite profile. Details of the proposed chemical structures and high-resolution mass spectra of all metabolites can be found in the Supporting Information (Figs. S2-S22).

Based on our results and previous reports ${ }^{32,35,36}$, the metabolic pathways involved in the transformation of cyantraniliprole in tomato plants are presented in Fig. 2. We observed that ring closure, followed by $\mathrm{N}$-demethylation were the prominent phase-I transformation pathways of cyantraniliprole in tomato plants, leading to the formation of IN-J9Z38 and IN-MLA84, respectively. The metabolite IN-J9Z38 then served as a key intermediate for several subsequent biotransformation reactions. Both IN-J9Z38 and IN-MLA84 were readily glycosylated to form the newly identified metabolites TP633 and TP619, respectively. Additionally, IN-J9Z38 and IN-MLA84 were dechlorinated and hydroxylated on the pyridine ring to form IN-RNU71 and TP423, respectively. IN-MLA84 could also be debrominated to form TP363. Oxidation at the cyano group of IN-J9Z38, followed by conjugation with the amino acid cysteine gave rise to the metabolite TP577. On the other hand, cyantraniliprole also underwent hydroxylation at the $N$-methyl group to form IN-MYX98 which was subsequently glycosylated to TP651. There were two signals with similar accurate $\mathrm{m} / z 651.061 \pm 0.001 \mathrm{Da}$, in which the $\mathrm{MS}^{2}$ fragmentation gave rise to identical product ions at $m / z 489.008 \pm 0.001 \mathrm{Da}$, which is the characteristic molecular ion of hydroxylated cyantraniliprole (Table 1). The isomeric signals of TP651 were denoted as TP651a (Fig. S17) and TP651b (Fig. S18), respectively. Although only IN-MYX98 was detected in this study, the second precursor hydroxylated metabolite was presumably IN-N7B69, which has commonly been observed in other plant species ${ }^{32}$. The metabolite IN-MYX98 could also be $N$-dealkylated to form IN-HGW87, the free amide of parent cyantraniliprole. In another pathway, the cyano group of cyantraniliprole underwent varying degrees of oxidation to amide (IN-JCZ38) and carboxylic acid (IN-JSE76) moieties. Glucose conjugation of IN-JSE76 was also observed, which was denoted as TP654. The breakdown metabolites IN-DBC80, IN-M2G98, and TP315, formed by cleavage of the carboxamide bridge between the phenyl and pyridine rings, could be from the parent cyantraniliprole or metabolites.

Distribution of cyantraniliprole metabolites in different plant tissues. The observed cyantraniliprole metabolites in tomato tissues could be the products of plant metabolism or soil degradants that 


\begin{tabular}{|c|c|c|c|c|c|c|c|c|c|c|}
\hline Denotation & Chemical formula & RT $(\min )^{a}$ & Calcd $m / z^{\mathrm{b}}$ & Obsd $m / z^{c}$ & Error (ppm) & Fragment ions $(m / z)^{d}$ & Leaves $^{e}$ & Flowers $^{\mathrm{f}}$ & Fruits $^{g}$ & Level $^{\text {h }}$ \\
\hline Cyantraniliprole & $\mathrm{C}_{19} \mathrm{H}_{14} \mathrm{BrClN}_{6} \mathrm{O}_{2}$ & 9.31 & 473.0123 & 473.0126 & 0.6 & 284,442 & + & + & + & 1 \\
\hline IN-J9Z38 & $\mathrm{C}_{19} \mathrm{H}_{12} \mathrm{BrClN}_{6} \mathrm{O}$ & 11.04 & 455.0017 & 455.0022 & 1.1 & $350,361,375,398,419$ & + & + & - & $2 \mathrm{~b}$ \\
\hline IN-RNU71 & $\mathrm{C}_{19} \mathrm{H}_{13} \mathrm{BrN}_{6} \mathrm{O}_{2}$ & 8.15 & 437.0356 & 437.0361 & 1.1 & $301,327,406$ & + & + & - & $2 \mathrm{~b}$ \\
\hline IN-HGW87 & $\mathrm{C}_{18} \mathrm{H}_{12} \mathrm{BrClN}_{6} \mathrm{O}_{2}$ & 8.30 & 458.9966 & 458.9972 & 1.3 & 284,442 & + & - & - & $2 \mathrm{~b}$ \\
\hline IN-JSE76 & $\mathrm{C}_{19} \mathrm{H}_{15} \mathrm{BrClN}_{5} \mathrm{O}_{4}$ & 8.40 & 492.0069 & 492.0077 & 1.6 & 284,461 & + & - & - & $2 \mathrm{~b}$ \\
\hline IN-JCZ38 & $\mathrm{C}_{19} \mathrm{H}_{16} \mathrm{BrClN}_{6} \mathrm{O}_{3}$ & 7.59 & 491.0228 & 491.0235 & 1.3 & 284,460 & + & + & - & $2 \mathrm{~b}$ \\
\hline IN-MLA84 & $\mathrm{C}_{18} \mathrm{H}_{10} \mathrm{BrClN}_{6} \mathrm{O}$ & 10.27 & 440.9861 & 440.9866 & 1.1 & $270,284,312,361,405$ & + & + & + & $2 \mathrm{~b}$ \\
\hline IN-MYX98 & $\mathrm{C}_{19} \mathrm{H}_{14} \mathrm{BrClN}_{6} \mathrm{O}_{3}$ & 8.44 & 489.0072 & 489.0078 & 1.2 & 442,471 & + & + & - & $2 \mathrm{~b}$ \\
\hline IN-DBC80 & $\mathrm{C}_{9} \mathrm{H}_{5} \mathrm{BrClN}_{3} \mathrm{O}_{2}$ & 7.77 & 301.9326 & 301.9328 & 0.7 & 258,284 & + & + & + & $2 \mathrm{~b}$ \\
\hline IN-M2G98 & $\mathrm{C}_{9} \mathrm{H}_{6} \mathrm{BrClN}_{4} \mathrm{O}$ & 7.32 & 300.9486 & 300.9486 & 0.0 & n.a & + & + & - & 5 \\
\hline TP315 & $\mathrm{C}_{10} \mathrm{H}_{8} \mathrm{BrClN}_{4} \mathrm{O}$ & 7.80 & 314.9643 & 314.9644 & 0.3 & 284 & + & + & - & 3 \\
\hline TP316 & $\mathrm{C}_{10} \mathrm{H}_{7} \mathrm{BrClN}_{3} \mathrm{O}_{2}$ & 10.11 & 315.9483 & 315.9486 & 1.0 & n.a & + & + & + & 5 \\
\hline TP363 & $\mathrm{C}_{18} \mathrm{H}_{11} \mathrm{ClN}_{6} \mathrm{O}$ & 8.99 & 363.0756 & 363.0760 & 1.1 & $206,234,270,327$ & + & + & - & 3 \\
\hline TP405 & $\mathrm{C}_{18} \mathrm{H}_{9} \mathrm{BrN}_{6} \mathrm{O}$ & 11.51 & 405.0094 & 405.0100 & 1.5 & 298,326 & + & - & - & 3 \\
\hline TP423 & $\mathrm{C}_{18} \mathrm{H}_{11} \mathrm{BrN}_{6} \mathrm{O}_{2}$ & 7.79 & 423.0200 & 423.0207 & 1.7 & $262,289,327,406$ & + & + & - & 3 \\
\hline TP441 & $\mathrm{C}_{18} \mathrm{H}_{10} \mathrm{BrClN}_{6} \mathrm{O}$ & 8.42 & 440.9861 & 440.9865 & 0.9 & 284,405 & + & - & - & 3 \\
\hline TP577 & $\mathrm{C}_{22} \mathrm{H}_{18} \mathrm{BrClN}_{6} \mathrm{O}_{4} \mathrm{~S}$ & 8.67 & 577.0055 & 577.0063 & 1.4 & n.a & + & + & - & 5 \\
\hline TP619 & $\mathrm{C}_{24} \mathrm{H}_{20} \mathrm{BrClN}_{6} \mathrm{O}_{7}$ & 6.95 & 619.0338 & 619.0347 & 1.5 & $403,439,457$ & + & + & + & 3 \\
\hline TP633 & $\mathrm{C}_{25} \mathrm{H}_{22} \mathrm{BrClN}_{6} \mathrm{O}_{7}$ & 7.67 & 633.0495 & 633.0503 & 1.3 & 471 & + & - & - & 3 \\
\hline TP651a & $\mathrm{C}_{25} \mathrm{H}_{24} \mathrm{BrClN}_{6} \mathrm{O}_{8}$ & 6.53 & 651.0600 & 651.0608 & 1.2 & $284,458,471,489$ & + & + & - & 3 \\
\hline TP651b & $\mathrm{C}_{25} \mathrm{H}_{24} \mathrm{BrClN}_{6} \mathrm{O}_{8}$ & 7.21 & 651.0600 & 651.0616 & 2.5 & $442,471,489$ & + & - & - & 3 \\
\hline TP654 & $\mathrm{C}_{25} \mathrm{H}_{25} \mathrm{BrClN}_{5} \mathrm{O}_{9}$ & 7.20 & 654.0597 & 654.0608 & 1.7 & $284,445,461,474,623$ & + & - & - & 3 \\
\hline
\end{tabular}

Table 1. Mass-spectral information and proposed chemical formulas of cyantraniliprole-transformation products identified by Compound Discoverer 3.1 and Mass Frontier 8.0 software. n.a: not available, $(+)$ :

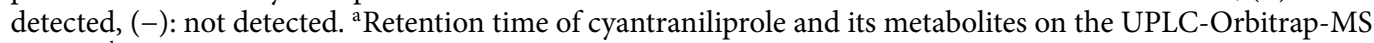
system. ${ }^{\text {b}}$ The accurate calculated masses $(\mathrm{calcd} \mathrm{m} / z$ ) were obtained with Chemsketch software, version 2019.1.2 (ACD/Laboratories, Toronto, ON). ${ }^{c}$ The observed masses (obsd $m / z$ ) were obtained from a highresolution MS (Thermo Orbitrap Fusion ${ }^{\text {tx }}$ Tribrid $^{\text {tw }}$ ). ${ }^{\mathrm{d}}$ The fragments ions acquired using data-dependent $\mathrm{MS}^{2}$ fragmentation in CID mode of the UPLC-Orbitrap-MS. e,f,g Detected in leaves, flowers, and fruits, respectively. ${ }^{\mathrm{h}}$ According to Schymanski et al. ${ }^{30}$ Level 1: reference standard, HR-MS, MS/MS, RT confirmed; Level 2b: HR-MS, characteristic fragmentation patterns observed; metabolites previously reported ${ }^{32}$; Level 3: HR-MS, characteristic fragmentation patterns observed, alternative structures (e.g., glycosylation positions) might be possible; Level 5: exact mass of interest.

were subsequently taken up. However, these metabolites were undetectable at all sampling intervals in xylem saps, suggesting that root-to-shoot translocation of cyantraniliprole metabolites was negligible, if any, and that transformation of cyantraniliprole in tomato plants primarily occurred in the above-ground plant tissues. Compared to young leaves, mature leaves were the major reservoir of cyantraniliprole metabolites. Cyantraniliprole metabolites were also detected in flower and fruit samples (Fig. 2); however, their occurrence in these tissues was quantitively lower than that in the foliage.

In order to visualize the variations of the metabolites in different tissues and sampling intervals, the intensity of each metabolite was normalized to that of cyantraniliprole at the corresponding sampling interval and presented as the metabolite-to-parent $(\mathrm{M} / \mathrm{P})$ ratio. Relative abundances of the tentatively identified cyantraniliprole metabolites in young and mature leaves, flowers, and fruits are shown in Fig. 3. The corresponding peak area data prior to normalization can be found in the Supporting Information (Fig. S25). In the foliage, the M/P ratios of all detected metabolites were $<10 \%$ up to 28 DAT, indicating that cyantraniliprole was relatively recalcitrant to metabolism. IN-J9Z38, IN-MLA84, and TP619 were found to be the major metabolites in mature leaves, and their relative abundances increased throughout the sampling period. The highest M/P ratios of IN-J9Z38, INMLA84 and TP619 were approximately $24.9,56.1$, and $17.7 \%$ at 84 DAT, respectively. The increase of these major metabolites in mature leaves could be partly explained by the enhanced biotransformation of cyantraniliprole, as well as depleted store of cyantraniliprole in the growth medium toward the conclusion of the experiment, leading to significant reduction of the parent insecticide residues in mature leaves (Fig. 1B). In young leaves, the $\mathrm{M} / \mathrm{P}$ ratios of both IN-J9Z38 and TP619 were $<10 \%$ across all sampling intervals, while those of IN-MLA 84 was approximately $15.2 \%$ at 84 DAT (Fig. 3), likely attributed to lower enzyme activity compared to mature leaves ${ }^{37}$. Both IN-J9Z38 and IN-MLA84 were also present as major residues in studies with rotational crops (e.g., wheat forage, hay, straw, and soybean foliage), while primary crop studies reported the formation of several low abundance metabolites ${ }^{32}$. We observed the occurrence of TP619, tentatively identified as a glycosylated conjugate of IN-MLA84, as a major metabolite of cyantraniliprole in tomato plants for the first time in this study. Apart from the foliage, IN-J9Z38, IN-MLA84, and TP619 were also detected in the flowers sampled at different times, with the highest M/P ratios at approximately 5.5, 6.2, and $0.9 \%$, respectively (Fig. 3 ). In the fruits, IN-J9Z38 was 


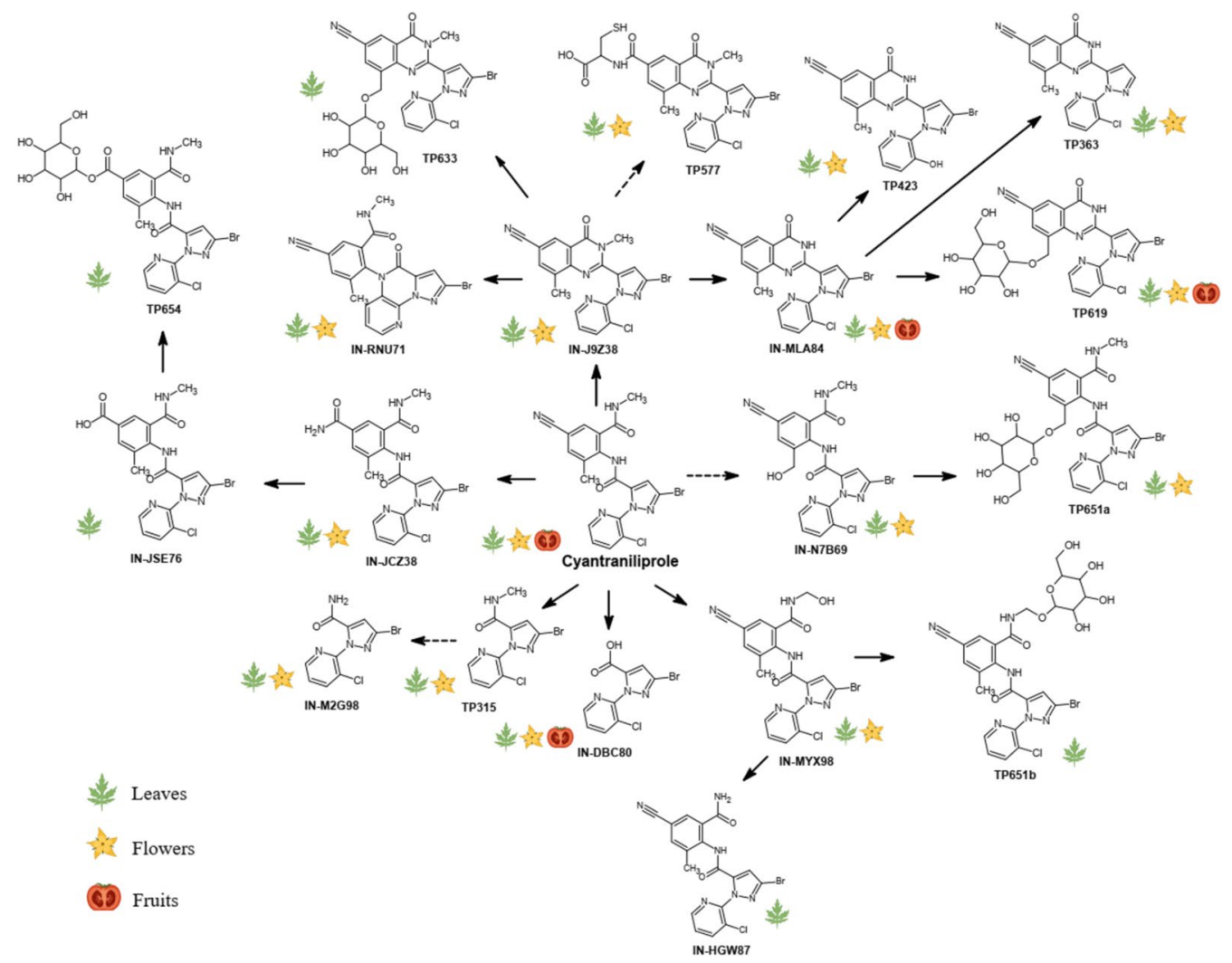

Figure 2. Proposed transformation pathways of cyantraniliprole in tomato plant tissues. Dashed arrows represent the pathways to the metabolites that have previously been reported ${ }^{32,35,36}$, or to the new metabolites identified in this study, in which their presence could not be unambiguously confirmed due to insufficient characteristic product ions acquired during $\mathrm{MS}^{2}$ fragmentation. The icons depicting leaves, flowers, and fruits indicate the occurrence of cyantraniliprole and its metabolites in the respective tissues.

undetectable at any developmental stages, whereas IN-MLA84 was found to be a major metabolite, with the M/P ratio increased from approximately $2.4 \%$ at the immature green stage (42 DAT) to approximately $16.3 \%$ at the red ripening stage (84 DAT) (Fig. 3), potentially as a result of the significant decline of cyantraniliprole residues in tomato fruits during the same period (Fig. 1D). In general, our data suggested that ring closure (IN-J9Z38), followed by $N$-dealkylation (IN-MLA84) and glycosylation (TP619) were the predominant transformation pathways of cyantraniliprole across different growth stages of the tomato plants treated through soil drench.

Additionally, there existed many minor metabolites which were detected mostly in the foliage and flowers of the treated tomato plants (Fig. 2). IN-J9Z38 and IN-MLA84 were proposed as the precursors of three dehalogenated metabolites, including IN-RNU71, TP363, and TP423. Their occurrence was observed in both leaves $(\mathrm{M} / \mathrm{P}$ ratios $<5 \%)$ and flowers (trace levels). Reductive dehalogenation is a common transformation pathway of halogenated xenobiotics following plant uptake, as have previously been reported for polychlorinated biphenyls, polybrominated diphenyl ethers, 1,2,5,5,6,9,10-heptachlorodecane, and triclocarban in maize ${ }^{38}$, $\operatorname{pumpkin}^{39,40}$, and jalapeno pepper ${ }^{41}$ plants, respectively.

Although hydroxylation of the parent xenobiotics, forming the metabolites that are more suitable for phaseII conjugation reactions, has been frequently observed, this transformation pathway might occur to a negligible extent in tomato plants upon soil application of cyantraniliprole. In this study, IN-MYX98 was the only hydroxylated cyantraniliprole detected in the tomato leaves and flowers, with the M/P ratios of $<0.5 \%$. Similarly, hydroxylation at the cyano group to amide (IN-JCZ38) and carboxylic acid (IN-JSE76) metabolites also exhibited the highest $\mathrm{M} / \mathrm{P}$ ratios of approximately $2.1 \%$ and $0.6 \%$ in mature leaves, respectively. Only trace levels of INJCZ38 were present in the flowers, while none of these hydroxylated metabolites were detectable in fruits at any developmental stages. In addition to TP619, other minor glycosylated conjugates were also observed, including TP633, TP651a, TP651b, and TP654. As shown in Fig. 3, these metabolites were largely present in mature leaves, with $\mathrm{M} / \mathrm{P}$ ratios ranging $0.1-3.4 \%$. Only TP651a was detected in flowers with $\mathrm{M} / \mathrm{P}$ ratios of $0.3-0.8 \%$.

In addition to the above-mentioned phase-I and phase-II metabolites, we also observed the presence of some breakdown products, such as IN-DBC80, IN-M2G98, and TP315 (Fig. 2). IN-DBC80 was detected at higher abundances in young leaves compared to mature leaves in all sampling intervals (Fig. 3). Its highest M/P ratios in young leaves were approximately $2.2 \%$ at $49 \mathrm{DAT}$, while the abundances in mature leaves were negligible. Interestingly, IN-DBC80 also exhibited similar M/P ratios in flowers, reaching approximately $2.5 \%$ at 49 DAT, and subsequently was found as the most abundant metabolite in fruits, with the M/P ratios ranging from 6.6 to $31.7 \%$ during $42-77$ DAT; however, the M/P ratio of IN-DBC80 was abruptly decreased to approximately $9.5 \%$ 

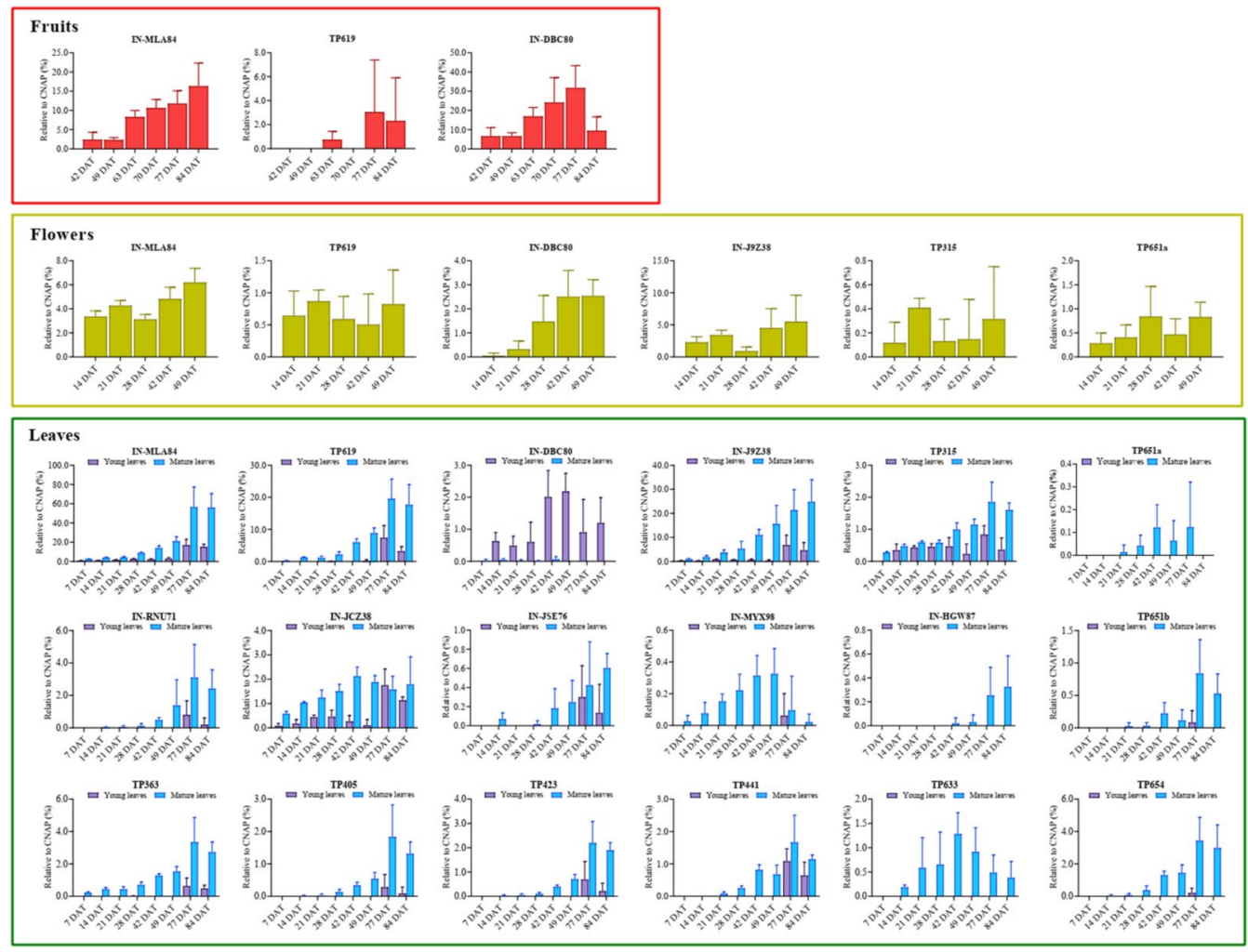

Figure 3. Relative abundances of cyantraniliprole metabolites detected in tomato leaves, flowers, and fruits throughout the experiments. For flowers, the metabolites that were only detectable in the concentrated extracts as described in the Materials and Methods, including IN-M2G98, IN-RNU71, IN-MYX98, IN-JCZ38, TP363, and TP423, are not presented due to their negligible abundance compared to parent cyantraniliprole. Also, other metabolites confirmed at the lowest confidence level (level 5, Table 1), including IN-M2G98, TP316, and TP577, are not presented for all plant tissues. The values represent the means \pm standard deviation $(n=5)$.

at the red ripening stage (84 DAT). Another frequently detected breakdown metabolite was TP315, which was present in leaves and flowers $(\mathrm{M} / \mathrm{P}$ ratios of $<2 \%)$, but undetectable in fruits at all sampling intervals.

Collectively, the results obtained from this study indicated that cyantraniliprole is relatively recalcitrant to plant metabolism. Over the course of the experiment, cyantraniliprole was the major residue in different tissues up to fruit maturity. The biotransformation processes primarily occurred in the above-ground biomass, especially in the mature leaves. Cyantraniliprole $\rightarrow$ IN-J9Z38 $\rightarrow$ IN-MLA84 $\rightarrow$ TP619 were the predominant transformation pathways of cyantraniliprole in tomato plants, as evident by their ubiquitous presence in leaves, flowers, and fruits at different times after treatment. Additionally, biotransformation of cyantraniliprole in tomato plants was also associated with several metabolites, including phase-I, phase-II, and other breakdown products, in low abundance. To our best knowledge, this study captures for the first time the metabolic fate of a diamide insecticide over the lifespan of a crop plant.

In this study, the highest cyantraniliprole concentrations were approximately $5.3 \mathrm{ng} / \mathrm{g}$ in green fruits and $1.4 \mathrm{ng} / \mathrm{g}$ in ripening fruits, which were substantially lower than the Maximum Residue Limit set by the U.S. EPA for fruiting vegetables $(2000 \mathrm{ng} / \mathrm{g})^{32}$. Recently, there have been growing concerns about human health risks associated with the presence of xenobiotic metabolites in plants ${ }^{42}$. IN-J9Z38 has frequently been observed as a major metabolite via abiotic degradation and plant metabolism of cyantraniliprole, and is required to be reported as the residue of concern for risk assessment in processed commodities ${ }^{32,36,43}$. Our data indicated that metabolism of cyantraniliprole in plants via soil drench occurred slowly, in which the M/P ratios of IN-J9Z38 in mature leaves were approximately $5.3 \%$ at 28 DAT. On the other hand, IN-J9Z38 was undetectable in fruits. It has been known that glycosylated metabolites are likely to be hydrolyzed, or further transformed by the gut microbes during digestion ${ }^{44}$. However, the metabolite TP619 was only present in the fruits at trace levels, suggesting that it is of a minor concern. Accordingly, in tomatoes, cyantraniliprole residue should be the focus for risk assessment, since none of the metabolites seems to accumulate in fruits.

\section{Materials and methods}

Standard of cyantraniliprole (purity 98.2\%) was purchased from Chemservice (West Chester, PA). The isotopelabeled $d_{3}$-cyantraniliprole (purity $>95 \%$ ) was purchased from Clearsynth (Mississauga, Ontario, Canada). MSgrade water, acetonitrile, and formic acid were purchased from Fisher Scientific (Waltham, MA). Analytical grade anhydrous sodium acetate $\left(\mathrm{CH}_{3} \mathrm{COONa}\right)$ and anhydrous magnesium sulfate $\left(\mathrm{MgSO}_{4}\right)$ were purchased 

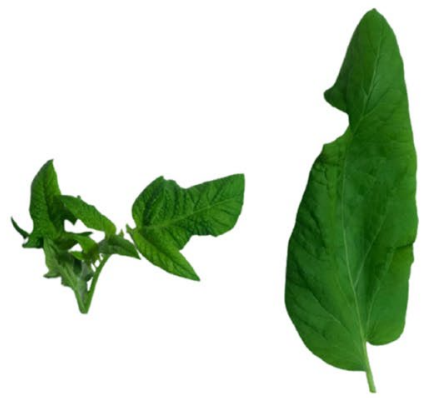

Young and mature leaves

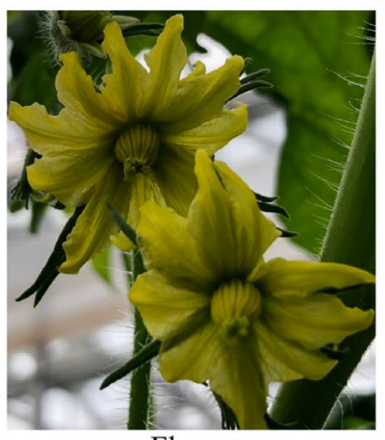

Flowers

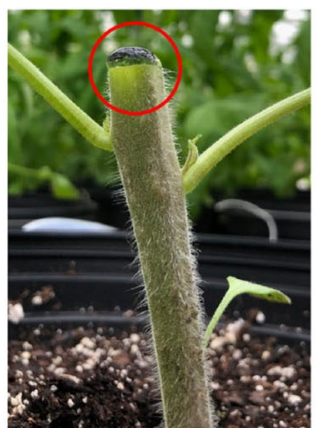

Xylem sap

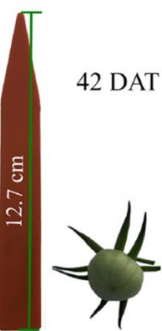

49 DAT

63 DAT
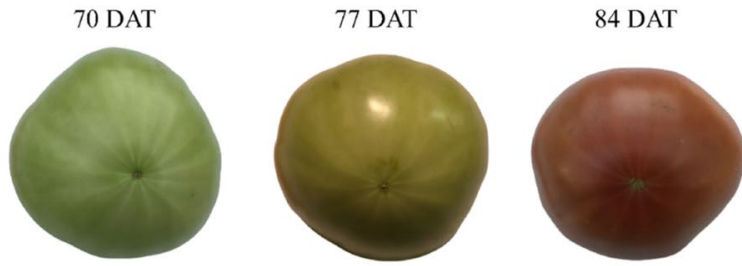

Fruits

Figure 4. Sampling scheme showing tomato young and mature leaves, flowers, xylem sap, and fruits at different developmental stages. DAT days after treatment.

from Sigma-Aldrich (St. Louis, MO). C18 endcapped bulk sorbent (Part No. 5982-5752) was obtained from Agilent Technologies (Santa Clara, CA).

Plant growth and insecticide application. The experiments were conducted in a greenhouse at Clemson University (Clemson, SC) from October 2019 to February 2020. The greenhouse was under natural light and maintained at average min-max temperature of $24-27^{\circ} \mathrm{C}$, and relative humidity of $60-70 \%$ during the treatment period. Tomato seeds (cv. "Black Sea Man") were obtained from Seed 'n Such (Graniteville, SC) and were sown three seeds in each plastic pot (28 cm diameter, $24 \mathrm{~cm}$ depth) filled with a standard nursery mix made of $55 \%$ peat moss, 30\% bark, and 15\% perlite (Metro-Mix 830; Sun Gro Horticulture, Agawam, MA). Germination was observed 5-7 days after sowing. Subsequently, seedlings at 2-3 leaf stage were thinned to one plant per pot. Plants were hand-watered as needed and fertilized with Miracle-Gro All Purpose fertilizer (24-8-6) every 1-2 weeks after application of cyantraniliprole until the conclusion of the experiments.

Tomato plants were treated with cyantraniliprole once via soil drench approximately four weeks after germination, using low application rate recommended for greenhouse-grown plants. Mainspring GNL (18.66\% cyantraniliprole; Syngenta Crop Protection LLC, Greensboro, NC) was diluted in water at the application rate of $0.63 \mathrm{~mL} / \mathrm{L}$ ( $8 \mathrm{fl}$. oz. formulated product per 100 gal.). Each pot in the treated group received $470 \mathrm{~mL}$ of the diluted solution (approximately $59 \mathrm{mg}$ of cyantraniliprole per pot). The control group received the same amount of water. Each group consisted of 40 plants, which were arranged in a completely randomized design on a greenhouse bench.

Plant tissue harvest. Xylem sap, leaves, flowers, and fruits were collected at 7 - to 14 -day intervals from 7 to 84 DAT (Fig. 4, Table S1). At each interval (except 63 and 70 DAT), 5 plants from each treatment were randomly selected and destructively sampled for both mature and young leaves. Mature, fully expanded leaves at different sides of the middle section of the plants were sampled, whereas young leaves (apical leaves) were collected from top of the plants. Three to four leaves were harvested from each plant and combined to form two composite samples per plant-one representing young leaves and the other representing mature leaves. Flowers were only sampled at full-open (anthesis) stage from 14 to 49 DAT. Fruits were harvested from immature green (42 DAT) to red ripening (84 DAT), in which 2-3 fruits of similar size were collected from each plant at each sampling interval. The samples were kept on dry ice before transport to the laboratory and stored at $-80{ }^{\circ} \mathrm{C}$ until analysis.

Collection of xylem sap was performed as previously described by Lowe-Power et al. ${ }^{45}$. Plants were wellwatered each evening before morning sampling to build up root pressure. One to three hours after sunrise, the plants were detopped at approximately $7 \mathrm{~cm}$ above the soil surface using a sharp razor to yield a flat stump surface, on top of which xylem sap accumulated as a droplet. To minimize contamination, the sap droplet accumulated in the first 2 min of detopping was discarded, and the stump was washed with deionized water and gently blotted dry with Kimwipes tissues. For the next $20 \mathrm{~min}$, the sap was frequently pipetted into a $2.0-\mathrm{mL}$ centrifuge tube kept on ice. The tubes were then stored at $-80^{\circ} \mathrm{C}$ until analysis. 
Sample preparation. Xylem sap was analyzed without further preparation. Leaves and flowers (approximately $0.5 \mathrm{~g}$ per sample) were weighed into 7 - $\mathrm{mL}$ tubes. Prior to extraction, internal standard $d_{3}$-cyantraniliprole was spiked into each sample at $120 \mathrm{ng} / \mathrm{g}$ fresh weight (fw). Sample homogenization was facilitated with the addition of 5 ceramic beads, $1.5 \mathrm{~mL}$ water, and $3.0 \mathrm{~mL}$ acetonitrile. The samples were then thoroughly homogenized at $6000 \mathrm{rpm}$ for 4 repetitions of 30 -s cycles using a homogenizer (Precellys Evolution, Bertin Instruments). The samples were centrifuged at $3000 \mathrm{rpm}$ for $5 \mathrm{~min}$, and the supernatant was transferred into new tubes containing $800 \pm 5 \mathrm{mg} \mathrm{MgSO}_{4}$ anhydrous and $200 \pm 5 \mathrm{mg} \mathrm{CH} \mathrm{COONa}_{3}$ anhydrous. The samples were vortexed at $2500 \mathrm{rpm}$ for $10 \mathrm{~min}$ and centrifuged at $3000 \mathrm{rpm}$ for $5 \mathrm{~min}$ to obtain transparent acetonitrile phase. For matrix removal, aliquots of $1.0 \mathrm{~mL}$ of the acetonitrile supernatant were transferred into clean 2.0 - $\mathrm{mL}$ tubes containing $200 \pm 5 \mathrm{mg}$ $\mathrm{C} 18$ sorbent and $150 \pm 5 \mathrm{mg} \mathrm{MgSO}_{4}$ anhydrous. The samples were shaken on a rotary shaker at $50 \mathrm{rpm}$ for $5 \mathrm{~min}$ and centrifuged at $14,000 \mathrm{rpm}$ for $10 \mathrm{~min}$. Finally, the supernatant was transferred into $2.0-\mathrm{mL}$ glass vials. For flowers, an additional concentration step ( 5 times) was performed by nitrogen blow-down and reconstitution to accurately verify the presence of low-abundant metabolites in the samples.

Fruits were homogenized in a blender, and aliquots of $5.0 \mathrm{~g}$ pulp were weighed into 50 - $\mathrm{mL}$ tubes. Prior to extraction, $d_{3}$-cyantraniliprole was spiked into each sample at a concentration of $4 \mathrm{ng} / \mathrm{g} \mathrm{fw}$. Acetonitrile $(10 \mathrm{~mL})$ was then added into each tube and the samples were vortexed at $2500 \mathrm{rpm}$ for $10 \mathrm{~min}$. Next, $4.0 \pm 0.1 \mathrm{~g}$ of $\mathrm{MgSO}_{4}$ anhydrous and $1.0 \pm 0.1 \mathrm{~g}$ of $\mathrm{CH}_{3} \mathrm{COONa}$ anhydrous were added, and the mixture was vortexed again for $10 \mathrm{~min}$ and centrifuged at $3000 \mathrm{rpm}$ for $5 \mathrm{~min}$. Aliquots of $1.5 \mathrm{~mL}$ of the supernatant were cleaned up with $\mathrm{C} 18$ sorbent and $\mathrm{MgSO}_{4}$ anhydrous as described above. Finally, $1.0 \mathrm{~mL}$ clean supernatant were transferred into 2.0- $\mathrm{mL}$ glass vials, dried under nitrogen gas, and reconstituted in $0.1 \mathrm{~mL}$ acetonitrile.

Cyantraniliprole quantification and metabolites screening. The extracts were analyzed on an Ultimate 3000 HPLC (Thermo Scientific, Waltham, MA) coupled with an Orbitrap Fusion Tribrid mass spectrometer (Thermo Scientific). Chromatographic separation was achieved using Acquity HSS-T3 column $(150 \times 2.1 \mathrm{~mm}$, $1.8 \mu \mathrm{m}$; Waters Corp., Milford, MA) maintained at $32^{\circ} \mathrm{C}$. The mobile phases consisted of (A) water and (B) acetonitrile, both containing $0.1 \%$ formic acid. The gradient program was: $0-1 \mathrm{~min}, 20 \% \mathrm{~B} ; 9 \mathrm{~min}, 95 \% \mathrm{~B} ; 9-12 \mathrm{~min}$, $95 \% \mathrm{~B} ; 12.01 \mathrm{~min}, 20 \% \mathrm{~B}$; and re-equilibration at $20 \% \mathrm{~B}$ for $4 \mathrm{~min}$. The flow rate was maintained at $0.2 \mathrm{~mL} / \mathrm{min}$ and the injection volume was $2 \mu \mathrm{L}$. The autosampler temperature was maintained at $8{ }^{\circ} \mathrm{C}$. The samples were introduced into mass spectrometer using a heated electrospray ionization (H-ESI) source operated in positive ionization mode. The H-ESI interface parameters were as follows: spray voltage, $3.5 \mathrm{kV}$; vaporizer, $300^{\circ} \mathrm{C}$; ion transfer tube, $300{ }^{\circ} \mathrm{C}$; sheath gas, $55 \mathrm{arb}$; aux gas, $10 \mathrm{arb}$; and sweep gas, $1 \mathrm{arb}$. XCalibur ${ }^{\mathrm{ru}} 4.0$ software (Thermo Scientific) was used for data acquisition.

Data were initially acquired using a full $\mathrm{MS}^{1}$ scan on the Orbitrap within a mass range of $150-1200 \mathrm{~m} / z$, with scan resolution set to 120,000 (FWHM), AGC of 400,000, and a maximum injection time of $50 \mathrm{~ms}$. The acquired data were used for primary screening of the metabolite candidates. Fragmentation of the metabolite candidates was subsequently performed using data-dependent $\mathrm{MS}^{2}$ collision-induced dissociation (CID) at $40 \%$ collision energy. The $\mathrm{MS}^{1}$ master scan was operated with a scan range of $120-1000 \mathrm{~m} / z$, with an Orbitrap resolution of 60,000 (FWHM), AGC of 200,000 and maximum injection time of $50 \mathrm{~ms}$. The data-dependent $\mathrm{MS}^{2}$ scan was performed for the $\mathrm{m} / \mathrm{z}$ values listed in the targeted mass inclusion filter containing all metabolite candidates with a mass tolerance of $25 \mathrm{ppm}$. The scan resolution for $\mathrm{MS}^{2}$ was set to 15,000 (FWHM), AGC of 100,000, and maximum injection time of $54 \mathrm{~ms}$.

All samples were immediately analyzed after extraction in one single batch, with QC sample containing cyantraniliprole at $12.5 \mathrm{ng} / \mathrm{mL}$ injected after every 15 samples. The relative standard deviations of all QCs were from 1.3 to $5.9 \%$. Quantification of cyantraniliprole residue in plant tissues was performed using data acquired from Orbitrap $\mathrm{MS}^{1}$ scan in selected ion monitoring mode. Cyantraniliprole was identified by retention time (RT $\pm 0.1 \mathrm{~min}$ ), accurate molecular ion at $m / z 473.0123$, and reference isotope ions at $\mathrm{m} / z 475.0101$ and 477.0074 (mass errors $<5 \mathrm{ppm})$. Stock solutions of cyantraniliprole and $d_{3}$-cyantraniliprole $(1 \mu \mathrm{g} / \mathrm{mL})$ were prepared in acetonitrile and stored at $-20^{\circ} \mathrm{C}$. Working standards $(0.8-800 \mathrm{ng} / \mathrm{mL})$ were freshly prepared prior to instrument analysis.

Recoveries of cyantraniliprole and potential plant matrix interference on quantification were determined by the ratio of internal standard $d_{3}$-cyantraniliprole concentration in the final extract to the nominal spiked concentration in each sample (e.i., $120 \mathrm{ng} / \mathrm{g}$ for leaves and flowers, and $4 \mathrm{ng} / \mathrm{g}$ for fruits, respectively). Our preliminary trials indicated that the conventional QuEChERS matrix removal procedure resulted in significant loss of some cyantraniliprole metabolites (e.g., glycosylated conjugates). Therefore, in this study, matrix was partly removed using only $\mathrm{C} 18$ sorbent to essentially preserve the metabolite pool. As a result, plant matrix effects on quantitative analysis were still observed to different extent depending on the type and age of the tissues. Consequently, the concentration of cyantraniliprole was corrected to the respective recovery rate of $d_{3}$-cyantraniliprole in each sample by multiplying the initial result obtained after analysis with a factor $[100 \% / \text { recovery } \%]^{46}$. In this study, the mean recoveries of $d_{3}$-cyantraniliprole for young leaves, mature leaves, flowers, green fruits, and red fruits were $92.6 \pm 8.3,81.0 \pm 9.9,105.7 \pm 8.5,74.1 \pm 17.1$, and $63.2 \pm 14.5 \%$, respectively.

Limit of detection (LOD) of cyantraniliprole in each plant matrix was determined using spiked samples approach ${ }^{47}$. The untreated sample matrices were spiked with cyantraniliprole at a nominal concentration of $2 \mathrm{ng} /$ $\mathrm{mL}$ which was approximately five times the initial instrument LOD. The method LOD was then determined as follow:

$$
\operatorname{LOD}(\mathrm{ng} / \mathrm{mL})=\mathrm{t}_{\alpha} \times S_{s}
$$


where $t_{\alpha}$ is the Student's $t$-value appropriate for a single-tailed 99th percentile $t$ statistic and a standard deviation estimate with $n-1$ degrees of freedom; for seven injections, $t_{\alpha}=3.143$. $S_{s}$ is the sample standard deviation of the replicate spiked sample analyses. Limit of quantification $(\mathrm{LOQ})=3.3 \times \mathrm{LOD}$.

The LOD and LOQ values of cyantraniliprole in different plant matrices and fresh biomass are provided in Table S2. On a fresh weight basis, the LOQ in young leaves, mature leaves, flowers, green fruits, and red fruits were $5.6,6.2,7.7,0.3$, and $0.4 \mathrm{ng} / \mathrm{g}$, respectively.

Concentrations of cyantraniliprole in xylem sap were quantified on a Shimadzu Prominence UFLC coupled with a Shimadzu 8040-triple quadrupole mass spectrometer, applying ESI in positive mode. Chromatographic separation was performed at room temperature on a Kinetex XB-C18 column $(150 \times 3 \mathrm{~mm}, 2.6 \mu \mathrm{m}$, Phenomenex). Water and acetonitrile, both containing $0.1 \%$ formic acid, were used as the mobile phase A and $\mathrm{B}$, respectively. The gradient program was: 0-2 min: $15 \%$ B; $8 \mathrm{~min}, 95 \% \mathrm{~B} ; 8-11 \mathrm{~min}$ : $95 \%$ B; $11.01 \mathrm{~min}: 15 \%$ $\mathrm{B}$; and re-equilibration at $15 \% \mathrm{~B}$ for $5 \mathrm{~min}$. The flow rate was maintained at $0.4 \mathrm{~mL} / \mathrm{min}$ and the injection volume was $2 \mu \mathrm{L}$. The interface voltage was set to $4.5 \mathrm{kV}$ and nitrogen was used as nebulizing gas $(3 \mathrm{~L} / \mathrm{min})$. The desolvation line and heat block temperatures were set to 250 and $400{ }^{\circ} \mathrm{C}$, respectively. The MRM transition $\mathrm{m} / \mathrm{z}$ $474.9 \rightarrow 285.9(\mathrm{CE}=15 \mathrm{~V})$ was used for quantification, while the transitions $m / z 474.9 \rightarrow 176.9(\mathrm{CE}=49 \mathrm{~V})$ and $\mathrm{m} / z 474.9 \rightarrow 111.9(\mathrm{CE}=55 \mathrm{~V})$ were used for confirmation. The LOD and LOQ values of cyantraniliprole in xylem sap were 0.3 and $1.1 \mathrm{ng} / \mathrm{mL}$, respectively.

Data processing for metabolite identification. Screening of cyantraniliprole metabolites was performed as previously described ${ }^{18}$. Briefly, $\mathrm{MS}^{1}$ scan data were processed by Compound Discoverer 3.1 software (Thermo Scientific), using a custom designed workflow as shown in Fig. S1. The $m / z$ signals present in the nontreated samples were eliminated from being screened as cyantraniliprole metabolites. The metabolite candidates were further processed via a $\mathrm{Cl} / \mathrm{Br}$ isotope filter, assuming the metabolites contained at least one $\mathrm{Cl}$ and/or one $\mathrm{Br}$ atom from the parent cyantraniliprole. Subsequently, Mass Frontier 8.0 software (Thermo Scientific) was used to generate the possible chemical formulas for the metabolite candidates identified by Compound Discoverer, with mass-accuracy errors of $<5 \mathrm{ppm}$ for the molecular ion $[\mathrm{M}+\mathrm{H}]^{+}$. Following the primary identification of the metabolite candidates, the proposed structures were further confirmed by the characteristic fragment ions (mass-accuracy errors $<5 \mathrm{ppm}$ ) acquired by data-dependent $\mathrm{MS}^{2}$ fragmentation. Annotation of the fragment ions was performed using Mass Frontier 8.0 and CFM-ID 3.0 web server ${ }^{48}$. The identification confidence was ultimately classified following the framework proposed by Schymanski ${ }^{30}$.

A list of cyantraniliprole metabolites was compiled from the literature (Table S3). The metabolites identified by Compound Discoverer were subsequently searched against the compiled list of metabolites using their accurate $\mathrm{m} / \mathrm{z}$ and the corresponding $\mathrm{MS}^{2}$ fragment ions. The remaining metabolites were annotated as newly identified transformation products (TPs). Due to the lack of reference standards, relative quantification of the tentatively identified metabolites (intensity cutoff at approximately $10^{4}$, with signal-to-noise ratio $>10$ ) compared to the parent cyantraniliprole were reported. The chromatograms of cyantraniliprole and metabolites at the levels of quantification are provided in Figs. S23 and S24.

Statistical analysis. Concentrations of cyantraniliprole in plant tissues were calculated based on fresh weight (fw). Analysis of variance (ANOVA) with Sidak's or Tukey's HSD post hoc tests were performed using GraphPad Prism 8.4.3 (GraphPad Software, San Diego, CA) to detect significant differences and separate means among plant tissues and sampling intervals $(\alpha=0.05)$.

Ethics statement. The tomato seeds used in this study is commercially available in the United States; therefore, this study does not contain any research requiring ethical consent or approval. Insecticide treatments and collection of plant samples complied with relevant institutional, national, and international guidelines and legislation.

\section{Data availability}

Data supporting the findings of this manuscript are available from the corresponding author upon reasonable request.

Received: 16 May 2021; Accepted: 2 September 2021

Published online: 03 November 2021

\section{References}

1. Schulz, R., Bub, S., Petschick, L. L., Stehle, S. \& Wolfram, J. Applied pesticide toxicity shifts toward plants and invertebrates, even in GM crops. Science 372, 81-84 (2021).

2. Erdogan, C., Velioglu, A. S., Gurkan, M. O., Denholm, I. \& Moores, G. D. Detection of resistance to pyrethroid and neonicotinoid insecticides in the greenhouse whitefly, Trialeurodes vaporariorum (Westw.) (Hemiptera: Aleyrodidae). Crop Prot. https://doi.org/ 10.1016/j.cropro.2021.105661 (2021).

3. Gong, P. et al. Field evolved resistance to pyrethroids, neonicotinoids, organophosphates and macrolides in Rhopalosiphum padi (Linnaeus) and Sitobion avenae (Fabricius) from China. Chemosphere 269, 128747. https://doi.org/10.1016/j.chemosphere.2020. 128747 (2021).

4. Szczepaniec, A., Varela, K. A., Kiani, M., Paetzold, L. \& Rush, C. M. Incidence of resistance to neonicotinoid insecticides in Bactericera cockerelli across Southwest U.S. Crop Prot. 116, 188-195. https://doi.org/10.1016/j.cropro.2018.11.001 (2019).

5. Saeed, R. et al. Field evolved resistance to pyrethroids, neonicotinoids and biopesticides in Dysdercus koenigii (Hemiptera: Pyrrhocoridae) from Punjab, Pakistan. Chemosphere 213, 149-155. https://doi.org/10.1016/j.chemosphere.2018.09.042 (2018).

6. Byrne, F. J. \& Redak, R. A. Insecticide resistance in California populations of the glassy-winged sharpshooter Homalodisca vitripennis. Pest. Manag. Sci. 77, 2315-2323. https://doi.org/10.1002/ps.6258 (2021). 
7. Willis, C. E. et al. Investigating the status of pyrethroid resistance in UK populations of the cabbage stem flea beetle (Psylliodes chrysocephala). Crop Prot. 138, 105316. https://doi.org/10.1016/j.cropro.2020.105316 (2020).

8. Schmidt-Jeffris, R. A. \& Nault, B. A. Anthranilic diamide insecticides delivered via multiple approaches to control vegetable pests: A case study in snap bean. J. Econ. Entomol. 109, 2479-2488. https://doi.org/10.1093/jee/tow219 (2016).

9. Jactel, H. et al. Alternatives to neonicotinoids. Environ. Int. 129, 423-429. https://doi.org/10.1016/j.envint.2019.04.045 (2019).

10. Zilnik, G., Kraus, D. A. \& Burrack, H. J. Translocation and persistence of soil applied chlorantraniliprole as a control measure for Chloridea virescens in tobacco plant Nicotiana tabacum. Crop Prot. https://doi.org/10.1016/j.cropro.2020.105413 (2021).

11. Teixeira, L. A. \& Andaloro, J. T. Diamide insecticides: Global efforts to address insect resistance stewardship challenges. Pestic. Biochem. Physiol. 106, 76-78. https://doi.org/10.1016/j.pestbp.2013.01.010 (2013).

12. Cordova, D. et al. Anthranilic diamides: A new class of insecticides with a novel mode of action, ryanodine receptor activation. Pestic. Biochem. Physiol. 84, 196-214. https://doi.org/10.1016/j.pestbp.2005.07.005 (2006).

13. Sun, J., Feng, N., Tang, C. \& Qin, D. Determination of cyantraniliprole and its major metabolite residues in pakchoi and soil using ultra-performance liquid chromatography-tandem mass spectrometry. Bull. Environ. Contam. Toxicol. 89, 845-852. https://doi. org/10.1007/s00128-012-0752-2 (2012).

14. Foster, S. P. et al. Susceptibility of standard clones and European field populations of the green peach aphid, Myzus persicae, and the cotton aphid, Aphis gossypii (Hemiptera: Aphididae), to the novel anthranilic diamide insecticide cyantraniliprole. Pest Manag. Sci. 68, 629-633. https://doi.org/10.1002/ps.2306 (2012).

15. Pes, M. P. et al. Translocation of chlorantraniliprole and cyantraniliprole applied to corn as seed treatment and foliar spraying to control Spodoptera frugiperda (Lepidoptera: Noctuidae). PLoS ONE 15, e0229151. https://doi.org/10.1371/journal.pone.0229151 (2020).

16. Cloyd, R. A., Bethke, J. A. \& Cowles, R. S. Systemic insecticides and their use in ornamental plant systems. Floric. Ornam. Biotech 5, 1-9 (2011).

17. Wu, C. C., Dong, F. S., Mei, X. D., Ning, J. \& She, D. M. Distribution, dissipation, and metabolism of neonicotinoid insecticides in the cotton ecosystem under foliar spray and root irrigation. J. Agric. Food Chem. 67, 12374-12381. https://doi.org/10.1021/acs. jafc.9b04664 (2019).

18. Huynh, K. et al. Dissipation and transformation of the diamide insecticide cyantraniliprole in ornamental snapdragon (Antirrhinum majus). Chemosphere 281, 130753. https://doi.org/10.1016/j.chemosphere.2021.130753 (2021).

19. Sharma, A. et al. Brassinosteroid-mediated pesticide detoxification in plants: A mini-review. Cogent Food Agric. 4, 1436212. https:// doi.org/10.1080/23311932.2018.1436212 (2018).

20. Bonmatin, J. M. et al. Environmental fate and exposure; neonicotinoids and fipronil. Environ. Sci. Pollut. Res. 22, 35-67. https:// doi.org/10.1007/s11356-014-3332-7 (2015).

21. Liu, N., Pan, X., Yang, Q., Ji, M. \& Zhang, Z. The dissipation of thiamethoxam and its main metabolite clothianidin during strawberry growth and jam-making process. Sci. Rep. 8, 15242. https://doi.org/10.1038/s41598-018-33334-w (2018).

22. Dai, J. et al. Dissipation pattern and safety evaluation of cartap and its metabolites during tea planting, tea manufacturing and brewing. Food Chem. 314, 126165. https://doi.org/10.1016/j.foodchem.2020.126165 (2020).

23. Wu, C. et al. Spatial and temporal distribution, degradation, and metabolism of three neonicotinoid insecticides on different parts, especially pests' target feeding parts of apple tree. Pest Manag. Sci. 76, 2190-2197. https://doi.org/10.1002/ps.5756 (2020).

24. Quinet, M. et al. Tomato fruit development and metabolism. Front. Plant. Sci. 10, 1554. https://doi.org/10.3389/fpls.2019.01554 (2019).

25. Anderson, J. J. et al. Uptake of cyantraniliprole into tomato fruit and foliage under hydroponic conditions: Application to calibration of a plant/soil uptake model. J. Agric. Food Chem. 61, 9027-9035. https://doi.org/10.1021/jf4025757 (2013).

26. FMC. Verimark" Insect Control. https://ag.fmc.com/us/en/insecticides-miticides/verimark-insect-control. Access Date: July 17, 2021.

27. Barry, J. D. et al. Movement of cyantraniliprole in plants after foliar applications and its impact on the control of sucking and chewing insects. Pest Manag. Sci. 71, 395-403. https://doi.org/10.1002/ps.3816 (2015).

28. Goldstein, M., Shenker, M. \& Chefetz, B. Insights into the uptake processes of wastewater-borne pharmaceuticals by vegetables. Environ. Sci. Technol. 48, 5593-5600. https://doi.org/10.1021/es5008615 (2014).

29. Vogg, G. et al. Tomato fruit cuticular waxes and their effects on transpiration barrier properties: Functional characterization of a mutant deficient in a very-long-chain fatty acid beta-ketoacyl-CoA synthase. J. Exp. Bot. 55, 1401-1410. https://doi.org/10.1093/ jxb/erh149 (2004).

30. Schymanski, E. L. et al. Identifying small molecules via high resolution mass spectrometry: Communicating confidence. Environ. Sci. Technol. 48, 2097-2098. https://doi.org/10.1021/es5002105 (2014).

31. Kind, T. \& Fiehn, O. Seven Golden Rules for heuristic filtering of molecular formulas obtained by accurate mass spectrometry. BMC Bioinform. 8, 105. https://doi.org/10.1186/1471-2105-8-105 (2007).

32. USEPA. Cyantraniliprole. Petition for the Establishment of Permanent Tolerances and Registration for Use on Brassica (cole) Leafy Vegetables (Group 5), Bulb Vegetables (Group 3-07), Bushberries (Group 13-07B), Oilseed (Group 20), Citrus Fruit (Group 10-10), Cucurbit Vegetables (Group 9), Fruiting Vegetables (Group 8-10), Leafy Vegetables (non-Brassica) (Group 4), Pome Fruit (Group 11-10), Stone Fruit (Group 12), Tree Nuts (Group 14), Tuberous and Corm Vegetables (Subgroup 1C), and Food/Feed Handling Establishments. Summary of Analytical Chemistry and Residue Data. Report No. EPA-HQ-OPP-2011-0668-0009 (Office of Chemical Safety and Pollution Prevention, 2013).

33. Lee, J., Jung, M. W., Shin, Y. \& Kim, J. H. Dissipation of the insecticide cyantraniliprole and its metabolite IN-J9Z38 in proso millet during cultivation. Sci. Rep. 9, 11648. https://doi.org/10.1038/s41598-019-48206-0 (2019).

34. Zhang, C. et al. Residues of cyantraniliprole and its metabolite J9Z38 in rice field ecosystem. Chemosphere 93, 190-195. https:// doi.org/10.1016/j.chemosphere.2013.05.033 (2013).

35. Sharma, A. K. et al. Photolysis of chlorantraniliprole and cyantraniliprole in water and soil: Verification of degradation pathways via kinetics modeling. J. Agric. Food Chem. 62, 6577-6584. https://doi.org/10.1021/jf5017175 (2014).

36. USEPA. Amendment-EFED Environmental Risk Assessment of Proposed New Global Chemical Cyantraniliprole on Bushberries, Citrus, Cotton, Oil Seeds, Pome Fruit, Stone Fruit, Tree Nuts, Vegetables (Bulb, Corm and Tuberous, Cucurbit, Fruiting, Leafy Brassica, and Leafy-Non-brassica), and Professional Products (Fly Baits, Indoor and Outdoor Insect Control for Public Health Pests such as Cockroaches, Ants, Flies, Termites, Nuisance Insect Pests, Turfgrass and Ornamentals, Tree Injection, and Production Greenhouse and Nursery Ornamentals). Report No. EPA-HQ-OPP-2011-0668-0008 (Office of Chemical Safety and Pollution Prevention, 2013).

37. Bailey, L. F. \& McHargue, J. S. Enzyme activity in tomato fruits and leaves at different stages of development. Am. J. Bot. 30, 763-766. https://doi.org/10.2307/2437549 (1943).

38. Wang, S., Zhang, S., Huang, H., Zhao, M. \& Lv, J. Uptake, translocation and metabolism of polybrominated diphenyl ethers (PBDEs) and polychlorinated biphenyls (PCBs) in maize (Zea mays L.). Chemosphere 85, 379-385. https://doi.org/10.1016/j.chemosphere. 2011.07.002 (2011).

39. Yu, M. et al. Metabolites of 2,4,4'-tribrominated diphenyl ether (BDE-28) in pumpkin after in vivo and in vitro exposure. Environ. Sci. Technol. 47, 13494-13501. https://doi.org/10.1021/es404144p (2013).

40. Li, Y. et al. Dechlorination and chlorine rearrangement of $1,2,5,5,6,9,10$-heptachlorodecane mediated by the whole pumpkin seedlings. Environ. Pollut. 224, 524-531. https://doi.org/10.1016/j.envpol.2017.02.035 (2017). 
41. Huynh, K., Banach, E. \& Reinhold, D. Transformation, conjugation, and sequestration following the uptake of triclocarban by jalapeno pepper plants. J. Agric. Food Chem. 66, 4032-4043. https://doi.org/10.1021/acs.jafc.7b06150 (2018).

42. Malchi, T., Maor, Y., Tadmor, G., Shenker, M. \& Chefetz, B. Irrigation of root vegetables with treated wastewater: Evaluating uptake of pharmaceuticals and the associated human health risks. Environ. Sci. Technol. 48, 9325-9333. https://doi.org/10.1021/es501 $7894(2014)$

43. USEPA. Cyantraniliprole: Chronic Aggregate Dietary (Food plus Drinking Water) Exposure and Risk Assessments for the First Food Uses in Support of a Section 3 Registration Action on Brassica (cole) Leafy Vegetables (Group 5), Bulb Vegetables (Group 3-07), Bushberries (Group 13-07B), Oilseed (Group 20), Citrus Fruit (Group 10-10), Cotton, Cucurbit Vegetables (Group 9), Fruiting Vegetables (Group 8-10), Leafy Vegetables (non-Brassica) (Group 4), Pome Fruit (Group 11-10), Stone Fruit (Group 12), Tree Nuts (Group 14), and Tuberous and Corm Vegetables (Subgroup 1C). Report No. EPA-HQ-OPP-2011-0668-0010 (Office of Chemical Safety and Pollution Prevention, 2013).

44. Koppel, N., Maini Rekdal, V. \& Balskus, E. P. Chemical transformation of xenobiotics by the human gut microbiota. Science 356, eaag2770. https://doi.org/10.1126/science.aag2770 (2017).

45. Lowe-Power, T. M. et al. Metabolomics of tomato xylem sap during bacterial wilt reveals Ralstonia solanacearum produces abundant putrescine, a metabolite that accelerates wilt disease. Environ. Microbiol. 20, 1330-1349. https://doi.org/10.1111/1462-2920.14020 (2018).

46. SANTE/12682/2019. Analytical Quality Control and Method Validation Procedures for Pesticide Residues Analysis in Food and Feed (2020).

47. USEPA. Tittle 40: Protection of Environment; Part 136-Guidelines Establishing Test Procedures for the Analysis of Pollutants; Appendix B to Part 136-Definition and Procedure for the Determination of the Method Detection Limit-Revision 2. Report No. EPA 821-R-16-006 (2016).

48. Allen, F., Pon, A., Wilson, M., Greiner, R. \& Wishart, D. CFM-ID: A web server for annotation, spectrum prediction and metabolite identification from tandem mass spectra. Nucl. Acids Res. 42, W94-W99. https://doi.org/10.1093/nar/gku436 (2014).

\section{Acknowledgements}

The authors are thankful to Taylor Martin for his assistance with insecticide application and greenhouse maintenance.

\section{Author contributions}

Study concept and design-K.H., J.-H.C., and N.T.; Data acquisition and analysis-K.H. and E.L.; Drafting manuscript-K.H.; Reviewing and editing manuscript, and funding acquisition-J.-H.C., C.P., and N.T. All authors read and approved the manuscript.

\section{Funding}

Funding for this project was provided by USDA-NIFA-SCRI Grant \#2016-51181-25399.

\section{Competing interests}

The authors declare no competing interests.

\section{Additional information}

Supplementary Information The online version contains supplementary material available at https://doi.org/ 10.1038/s41598-021-00970-8.

Correspondence and requests for materials should be addressed to N.T.

Reprints and permissions information is available at www.nature.com/reprints.

Publisher's note Springer Nature remains neutral with regard to jurisdictional claims in published maps and institutional affiliations.

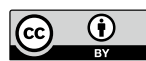

Open Access This article is licensed under a Creative Commons Attribution 4.0 International License, which permits use, sharing, adaptation, distribution and reproduction in any medium or format, as long as you give appropriate credit to the original author(s) and the source, provide a link to the Creative Commons licence, and indicate if changes were made. The images or other third party material in this article are included in the article's Creative Commons licence, unless indicated otherwise in a credit line to the material. If material is not included in the article's Creative Commons licence and your intended use is not permitted by statutory regulation or exceeds the permitted use, you will need to obtain permission directly from the copyright holder. To view a copy of this licence, visit http://creativecommons.org/licenses/by/4.0/.

(C) The Author(s) 2021 